\title{
Zor taşlarda zor bir metod: Mekanik litotripsi, Şişli Etfal Hastanesi deneyimi
}

Difficult method for difficult stones: Mechanical lithotripsy, Şisli Etfal Education and Training Hospital experience

Meltem ERGÜN, Ali Rıza KÖKSAL, Osman ÖZDOĞAN, Salih BOĞA, Mehmet BAYRAM, Hüseyin ALKIM, Canan ALKIM

Şişli Hamidiye Etfal Eğitim ve Araştırma Hastanesi, Gastroenteroloji Kliniği

Giriş ve Amaç: Endoskopik sfinkterotomi, balon ve basket kateterler yardımıyla koledok taşlarının \%85-90'ı temizlenebilmektedir. Büyük taşlarda, impakte taşlarda, çok sayıda taşı olan hastalarda standart tedavi ile başan1 güçtür. Zor taşlar için kullanılan metodlardan biri de mekanik litotripsi yöntemidir. Biz de kliniğimizde mekanik litotripsi yönteminin etkinliği ve güvenilirliğini retrospektif olarak incelemeyi amaçladık. Gereç ve Yöntem: Çalışmaya Ağustos 2011 ile Ağustos 2014 arasında Şişli Hamidiye Etfal Eğitim ve Araştırma Hastanesi Gastroenteroloji Endoskopi ünitesinde mekanik litotripsi yapılmış olan 18 hasta alındı. Hastaların demografik özellikleri, laboratuvar değerleri, hastalara yapılan ișlemler, işlem sonrası klinik seyir ve işlem komplikasyonlan retrospektif olarak değerlendirildi. Bulgular: Me kanik litoripsi işlemi 22-68 yas arası 18 hastaya (11'i kadın) uygulanmıstır. Hastaların 16'sında endoskopik sfinkterotomi yapılmıs, balonla koledok temizlenmiş, basket kateterle taş parçalanmaya çalıșılırken basket kateter koledokta sıkışmış ve mekanik litotripsi işlemine geçilmiştir. 2 hastada ise köşeli ve büyük taşlar bilindiğinden direkt olarak through the scope mekanik litotriptör ile taşlar kırılmıştır. Skop dışından mekanik litotripsi yapılan hastaların 15'ünde (\%83) litotripsi işlemi başarıyla gerçekleștirilirken, 2 hastada baskette kırılma meydana gelmiştir. Bir hastada ise mekanik litotripsiy takiben özofagus alt uçta perforasyon saptanmıștır. Endoskopik retrograd kolanjiopankreatikografi işlemi, mekanik litotripsi ve anesteziye bağlı mortalite görülmemiştir. Sonuç: Mekanik litotripsi, papilladan çıkmayacak kadar büyük taşların kırılarak küçültülmesi amacılla planlı veya basketle koledok taşlarının temizlenmesi esnasında, basketin koledok içinde sıkışması nedeniyle plansız ve zorunlu olarak taşı kırmak maksadıyla kullanılır. Zor, deneyim gerektiren, literatürde başarı oranı \%70-80 olarak bildirilen bir işlemdir. Bizim olgularımızda da \%83 tedavi başarısı etkin bir metod olduğunu göstermekte ancak riskleri de beraberinde getirmektedir

Anahtar kelimeler: Mekanik litotripsi, ERCP, koledokolitiazis

\section{GIIRISS}

Endoskopik retrograd kolanjiopankreatikografi (ERCP) koledok taşlarının temizlenmesinde birincil tedavi yöntemidir (1). Yeterli sfinkterotomiyi takiben balon ve/veya basketle taşlar olguların \%85-90'ında çıkarılabilmektedir. Kalan \%5-10 olguda da ileri ERCP metotları ile (mekanik litotripsi, elektrohidrolik şok dalgaları, lazer litotripsi) veya perkütan metodlar ve cerrahi metotlarla başarıya ulaşılmaktadır (2-4). Taşın 1 cm'den daha büyük olması, çok sayıda olması ve köşeli taşlar zor taş olarak sinıflandırılmaktadır (Resim 1,2). Koledok çapından daha büyük olan taş boyutu da yine çıkarılması zor taş grubunu oluşturmaktadır (5). Mekanik litotripsi, papilla-
Background and Aims: Common bile duct stones were successfully extracted in $85-90 \%$ of cases using endoscopic retrograde cholangiopancreatography procedures with balloons and basket catheters. However, endoscopic stone removal becomes challenging and sometimes impossible in the presence of a large, angled or multiple stones. The mechanical lithotripsy method is a procedure used to crush difficult to treat common bile duct stones. We retrospectively analyzed efficacy and safety of mechanical lithotripsy at our single center. Materials and Methods: Between August 2011 and August 2014, mechanical lithotripsy procedures were performed in 18 cases in the Sisli Etfal Education and Training Hospital Gastroenterology Department. Demographic features, laboratory tests, clinical course, procedure type and complications were retrospectively analyzed. Results: Mechanical lithotripsy was performed in 18 patients (Age: 22-68; 11 females, 7 males). In 16 patients, an endoscopic sphincterotomy was performed and the common bile duct was swept with a balloon catheter. While stone fragmentation was being performed with a basket catheter, the entrapped stone was impacted within the mid-common bile duct. A mechanical lithotripteur was used to crush the stone. In two patients with large stones, mechanical lithotripteur was performed after sphincterotomy. Mechanical lithotripsy was successful in 15 (83\%) patients; however, in two patients the wire of the mechanical lithotriptor snapped. Unfortunately, an esophageal perforation occurred in one patient. A metallic esophageal stent was placed and the patient recovered in one month. There were no mortalities in our mechanical lithotripsy cases. Conclusion: Mechanical lithotripsy is useful to crush difficult common bile duct stones in routine endoscopic retrograde cholangiopancreatography exams and also as a rescue procedure. It is a difficult procedure that requires considerable technical expertise. The success rate was 70-80\% for cases performed by those with experience; it is widely available in many parts of the world. The success rate was $81 \%$ in our series, despite some complications.

Key words: Endoscopic mechanical lithotripsy, ERCP, common bile duct stones

dan çıkmayacak kadar büyük taşların kırılarak küçültülmesi amacıyla planlı veya basketle koledok taşlarının temizlenmesi esnasında, basketin koledok içinde sıkışması nedeniyle plansız ve zorunlu olarak taşı kırmak maksadıyla kullanılır (6-7). Koledok içinde takılı kalmış basket üzerinden metal bir kılıf geçirilerek floroskopik kontrol ile mekanik kırıcı parça yavaşça döndürülerek taş parçalanır ve basket telleri koledok içinden kurtulur (Resim 5,6). Biz de kliniğimizde mekanik litotripsi uygulamalarımızın etkinliği ve güvenilirliğini retrospektif olarak araştırdık. 


\section{GEREC VE YÖNTEM}

Çalışmaya Ağustos 2011 ile Ağustos 2014 arasında Şişli Etfal Eğitim ve Araştırma Hastanesi Gastroenteroloji Endoskopi ünitesinde mekanik litotripsi yapılmış olan 18 hasta alındı. Hastaların demografik özellikleri, laboratuvar değerleri, hastalara yapılan işlemler, işlem sonrası klinik seyir ve işlem komplikasyonları retrospektif olarak değerlendirildi.

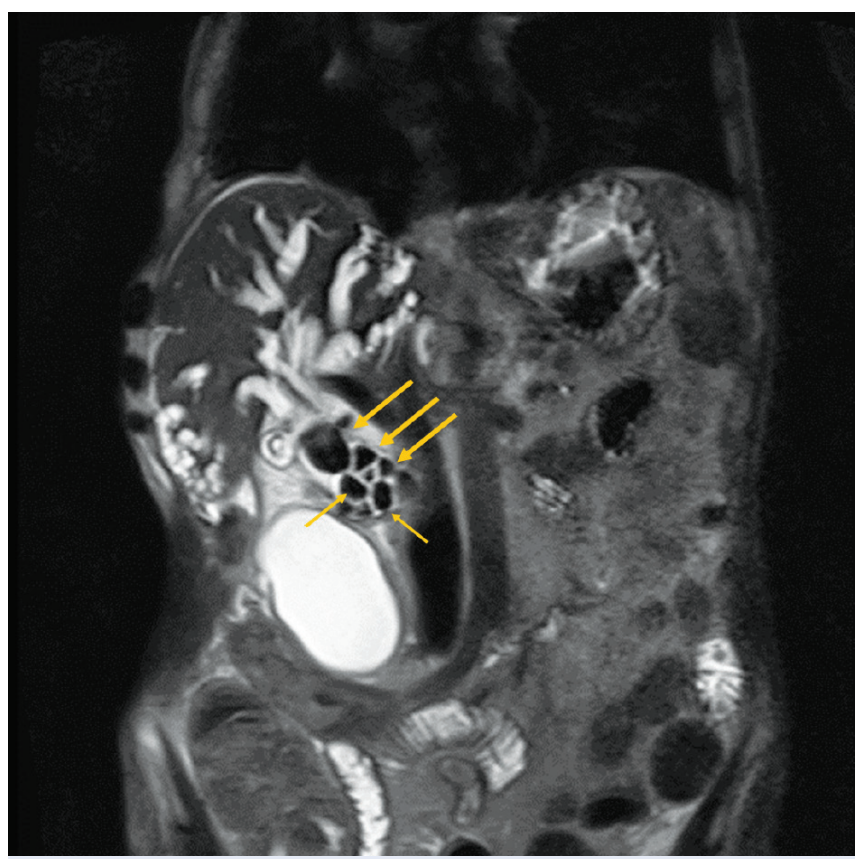

Resim 1. Magnetik rezonans incelemesinde koledokta çok sayıda taşlar.

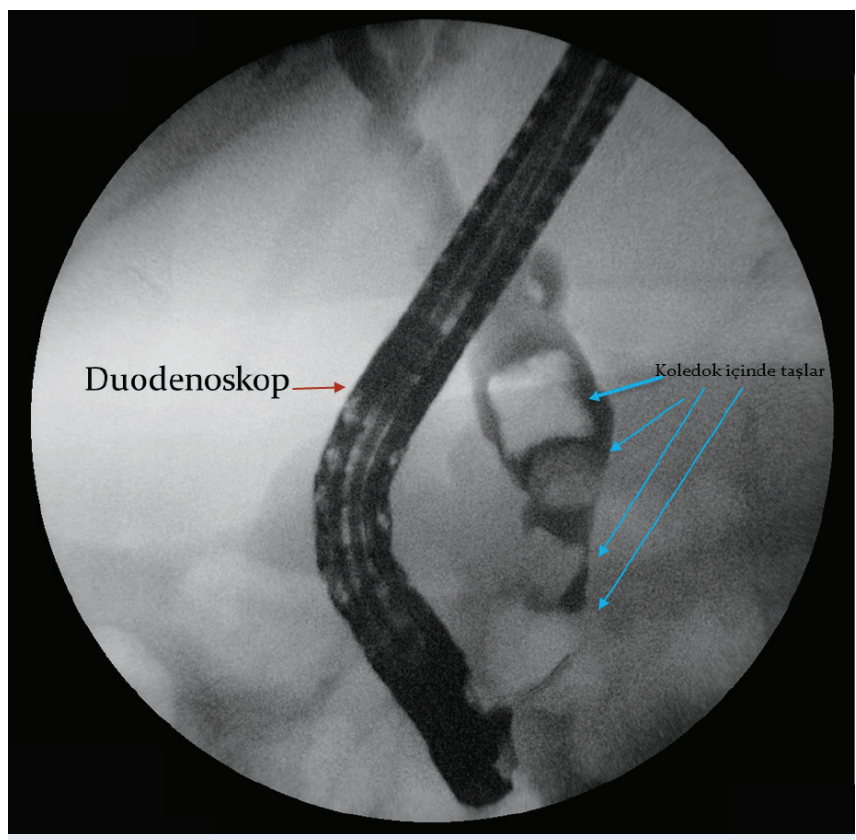

Resim 2. ERCP incelemesinde koledok içinde çok sayıda ve kare taşlar izleniyor.

\section{SONUCLAR}

Mekanik litoripsi işlemi 22-68 yaş arası 18 hastaya (11'i kadın) uygulanmıştır. Hastaların 16'sında endoskopik sfinkterotomi yapılmış, balonla koledok temizlenmiş, basket kateterle taş parçalanmaya çalışılırken basket kateter koledokta sıkışmış ve eksternal mekanik litotripsi işlemine geçilmiştir. Iki hastada ise büyük ve köşeli taşları olduğu görüldükten sonra, elimizde internal mekanik litotriptörün bulunmasının da katkısıyla, planlı şekilde mekanik litotripsi uygulanmıştır. Hastaları 15 'inde (\%83) litotripsi işlemi başarıyla gerçekleştirilmiş, koledoktaki taşlar kırılarak temizlenmiştir. Ancak 2 hastada litotripsi sırasında baskette kırlma, 1 hastada ise özofagusta perforasyon meydana gelmiştir.

Bir hastada basketteki kopma handle bölgesinden olmuş, basketin teli nazobiliyer drenaj kateteri gibi burundan dışarı alınarak, beklenmiş, bir hafta sonra tekrar ERCP yapıldığında basketin taştan kurtularak duodenuma düştüğü görülmüştür. Koledok opakla kontrol edildiğinde taşın kırılmış olduğu görülüp, kırılan parçalar temizlenmiştir.

Diğer hastada ise kırılma basketin distal ucuna yakın kısımda ortaya çıkmıs, bu hastada koledoğa plastik stent konularak beklenmiş. Iki hafta sonra basket telleri, stent ve taş ekstrakte edilmiştir (Resim 1-8).

Mekanik litotripsi yapılan 18 hastadan birinde, eksternal mekanik litotripsi sonrası tekrar duodenoskopla girildiğinde özofagus alt uçta 2 cm'lik perforasyon alanı saptanmış ve özofagusa kaplı metalik stent yerleştirilmiştir. Üç hafta sonra metalik stent de çıkarılmış ve hasta sorunsuz taburcu edilmiștir.

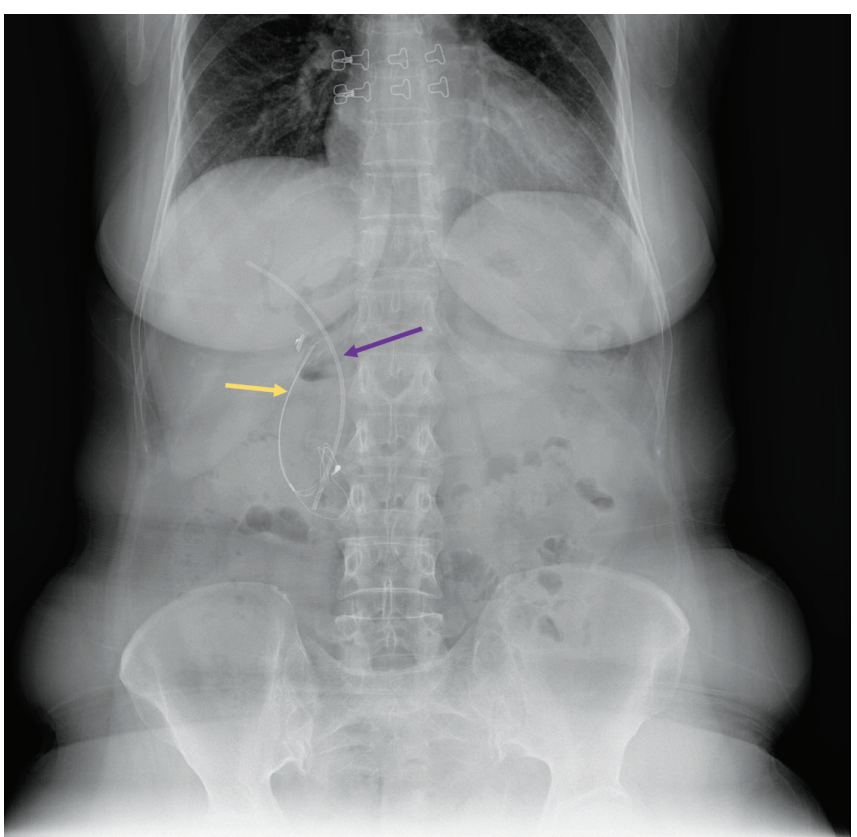

Resim 3. ERCP işlemi sırasında kırılan basket (Sarı ok) ve yanına konmuş plastik stent (Mor ok) 
Bu hastada koledoktaki kırılmış taşın temizlenmesi için tekrar ERCP yapılmadığından, koledok temizlenmesi başarısız olarak kabul edimiştir.

ERCP işlemi, mekanik litotripsi ve anesteziye bağl mortalite saptanmamıştır. Hastaların 8'inde 2 seans ve 3 'ünde ise 3 seans ERCP işlemi ile taşlar tamamen temizlenebilmiştir.

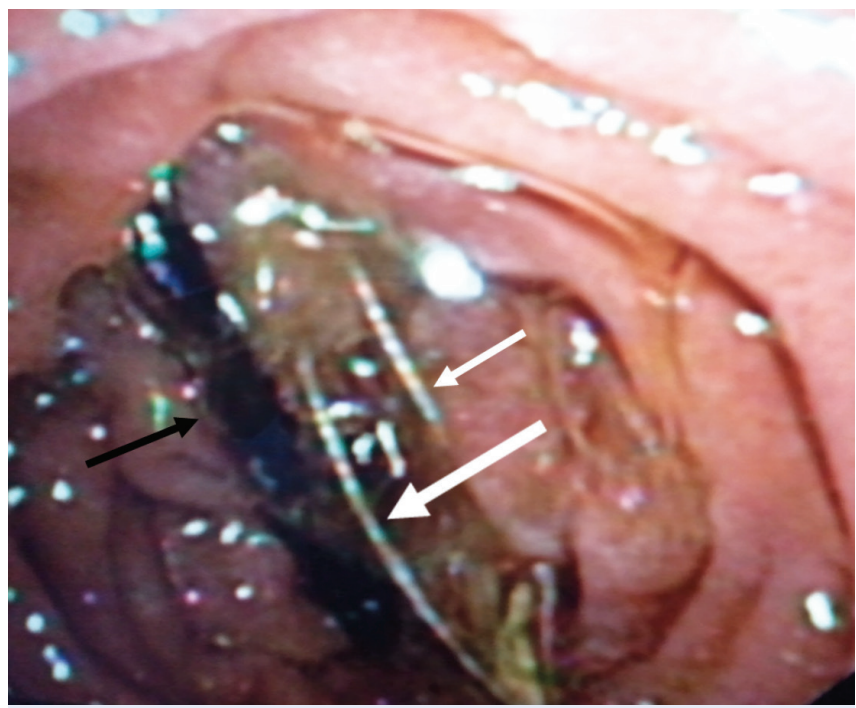

Resim 4. Ikinci seans ERCP'de koledoktan dışarı uzanan basket telleri ve plastik stent izleniyor.

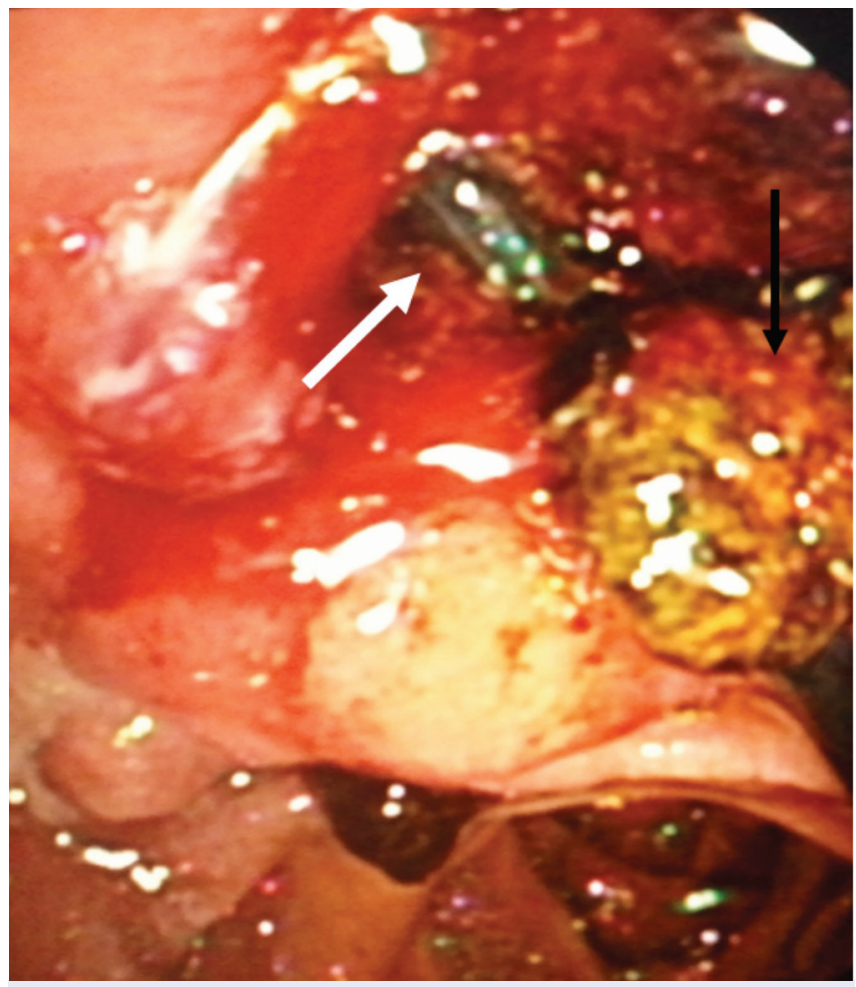

Resim 5. Ikinci seans ERCP'de koledoktan dışarı uzanan stent ve taş izleniyor.

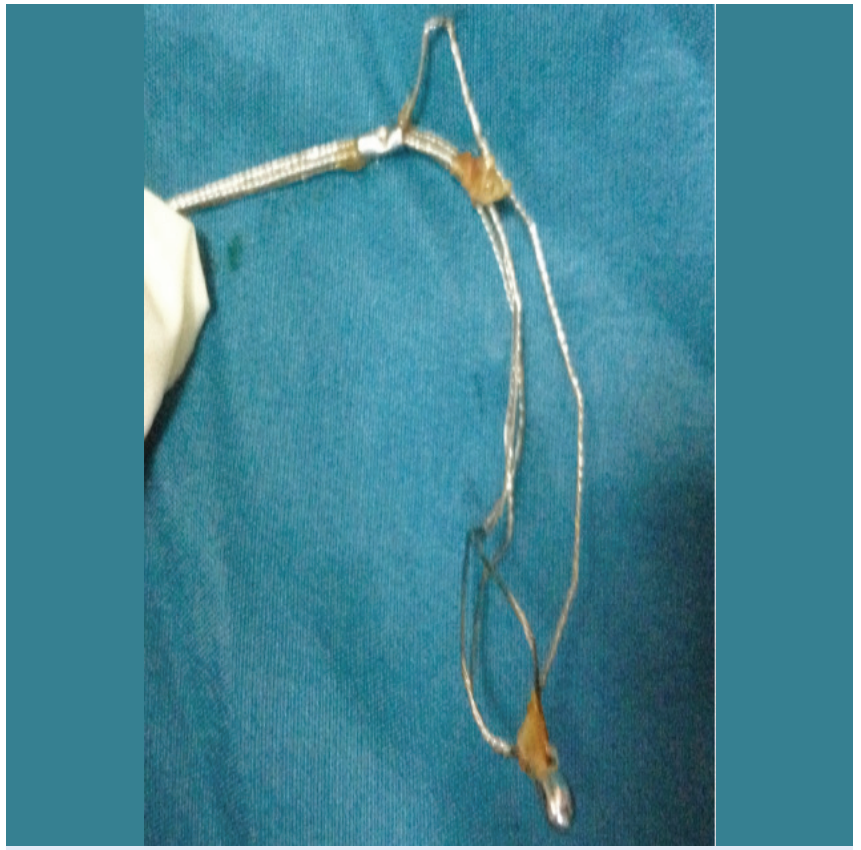

Resim 6. Ikinci seansta dışarı alınabilen basketin deforme olmuş hali.

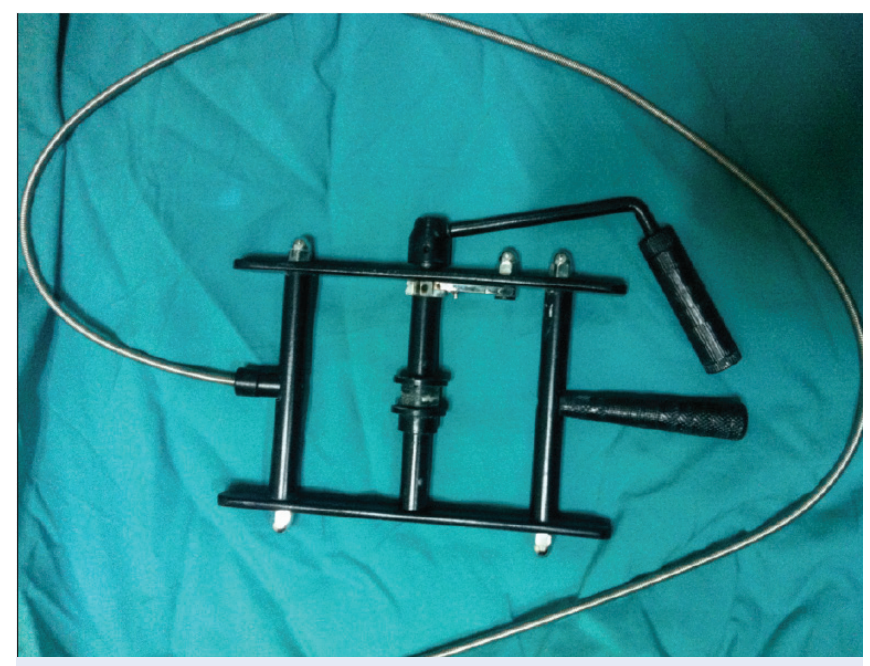

Resim 7. Mekanik litotripsi aleti.

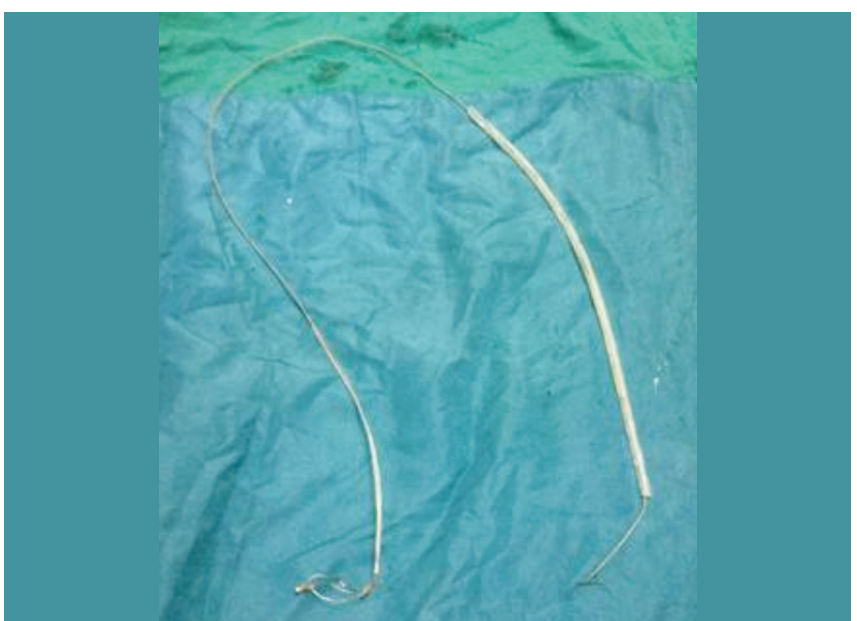

Resim 8. Diğer hastada handle bölgesinden kopmuş basket. 


\section{TARTISMA}

ERCP işlemi ile koledoktaki taşların yaklaşık \%90'ı temizlenebilmektedir (1). ERCP'de taş ekstraksiyonu için standart olarak sfinkterotomi, balon ve basket uygulanmaktadır. Ancak basket kullanımı zaman zaman işleri oldukça güçleştirmektedir. Basketin yakalayıp da kıramadığı sert taşlar, koledok içinde basketle birlikte sıkışmaktadır. Bu ERCP'yi yapan endoskopist için kötü bir kâbus gibidir. Ne var ki, bu zor durumda kullanılan metotlardan biri eksternal mekanik litotripsidir $(2,3)$. Daha fazla mekanik güç oluşturarak taşın kırılmasını sağlamaktadır. Nadir olarak basket tellerinde kopma olabilse de genellikle kâbusu, mutlu sona dönüştürebilmektedir.

Literatürde basket ile taş çıkarılması sırasında basketin sıkıştığı olgular bildirilmiştir. Bu hastalarda daha çok merkezde bulunabilen mekanik litotriptör en sık kullanılan yöntemdir. Diğer tedavi modaliteleri ise elektro-hidrolik probe litotripsi, ekstrakorporeal şok dalga litotripsi (ESWL) ve laser litotripsidir (4-6). Basketin sıkıştığı olgularda ESWL ile tek seansta taş kırılma başarısı 11/12 olguda saptanmıştır. Endoskopik intrakorporeal electrohidraulic shock wave lithotripsi tek tek olgu sunumu şeklinde bildirilmiştir ve başarılı olduğu belirtilmektedir (7). Ancak bu tedavi yöntemleri pek çok merkezde bulunmamaktadır. Ülkemizde de çok sinırlı merkezlerde yapılabilmektedir. Sıkışmış taş için uygulanabilecek bir diğer yöntem de cerrahidir, laparotomi ve koledokotomi yapılarak taş alınabilir (8).

Mekanik litotripsi işlemi sıkışmış taş ve basket kombinasyonunda kurtarıcı bir metod olarak kullanılmakla birlikte zor taş grubunda direkt olarak da seçilebilecek bir yöntemdir. Zor taş olarak adlandırılan büyük (çapı $>2 \mathrm{~cm}$ ), yahut koledok çapından daha geniş olan taşlar, köşeli taşlar; çok sayıda taşlardır. Bu zor taşlar için sfinkterotomi nispeten daha genişçe yapılıp, balon küçük küçük şişirilerek distal taşlar önce temizlenmeli ve giderek daha proksimale doğru yönelinmelidir. Zor taşların temizlenmesi için sabırla işlem yapılmalıdır. Bir seansta işlem tamamlanamayacaksa stent konulup işlem sonlandirılmalı ve sonraki seansta temizlemeye devam edilmelidir. Koledokta onlarca taş olan hastalarda ikiden çok seans da gerekebilir. Bu grup hastalar için 'through the scope' (endoskopun içinden geçen) litotriptörler de oldukça iyi bir seçenek oluşturmaktadır.

Mekanik litotripsi işlemi zor taşların tedavisinde, özellikle koledokta sıkışmış basket için birinci basamak kurtarıcı tedavidir. Endoskopistler için stresli bir işlem olsa da genellikle başarılıdır ve tecrübeli ekiplerde nadiren komplikasyonlara yol açmaktadır.

\section{KAYNAKLAR}

1- ASGE Technology Committee, Adler DG, Conway JD, Farraye FA, et al. Biliary and pancreatic stone extraction devices. Gastrointest Endosc 2009;70:603-9.

2. Chung SC, Leung JW, Leong HT, et al. Mechanical lithotripsy of large common bile duct stones using a basket. Br J Surg 1991;78:1448-50.

3- Ryozawa S1, Iwano H, Taba K, et al. Successful retrieval of an impacted mechanical lithotripsy basket: a case report. Dig Endosc 2010;22 (Suppl 1):S111-3.

4- Neuhaus H, Hoffmann W, Classen M. Endoscopic laser lithotripsy with an automatic stone recognition system for basket impaction in the common bile duct. Endoscopy 1992;24:596-9.

5- Schutz SM, Chinea C, Friedrichs P. Successful endoscopic removal of a severed, impacted Dormia basket. Am J Gastroenterol 1997;92:679-81.

6- Attila T, May GR, Kortan P. Nonsurgical management of an impacted mechanical lithotriptor with fractured traction wires: endoscopic intracorporeal electrohydraulic shock wave lithotripsy followed by extra-endoscopic mechanical lithotripsy. Can J Gastroenterol 2008;22:699-702.

7- Ng EK, Lau JY, Chung SC, Li AK. Retrieval of an impacted mechanical lithotripsy basket. Endoscopy 1997;29:128.

8- Allen N, Pettit S, Ali A. Stubborn stones: breakages of a mechanical lithotripter by an exceptionally hard gallstone. BMJ Case Rep 2014;2014. pii: bcr2014204940. 